\title{
Pre-Shopping Habits and Consumer Vulnerability in Food Retailing
}

\author{
Sylvain Charlebois ${ }^{1}$, Sarah Chamberlain ${ }^{2} \&$ Ayesha Herian $^{2}$ \\ ${ }^{1}$ Faculty of Agriculture, Dalhousie University, Truro, Nova Scotia, Canada \\ ${ }^{2}$ Faculty of Management, Dalhousie University, Halifax, Nova Scotia, Canada \\ Correspondence: Sylvain Charlebois, Kenneth C. Rowe Management Building, Room 3059, 6100 University \\ Avenue, PO Box 15000, Halifax NS, B3H 4R2, Canada. E-mail: sylvain.charlebois@ dal.ca
}

Received: May 4, 2018

Accepted: May 25, 2018 Online Published: June 20, 2018

doi:10.5539/jfr.v7n5p24

URL: https://doi.org/10.5539/jfr.v7n5p24

\begin{abstract}
Food prices in Canada have reached uncharacteristic highs in the last two years. Seven-dollar heads of cauliflower in 2016 became the poster-vegetable of the costs of food prices and questions arose about how Canadian consumers were assessing and mitigating their vulnerability. This study surveyed just over 1000 Canadians in all regions of Canada, including the North, to assess perceived vulnerability of Canadian consumers to rises in food prices and determine the behavioural changes that occurred to mitigate vulnerability. We found that Canadians generally felt more vulnerable to fluctuating food prices and that certain demographic traits, such as age, income, geographic location, and family status did have an impact on degree of vulnerability and what methods consumers would use to try to adapt to price volatility. Some consumer groups were more vulnerable than others, but consumers demonstrated awareness of and ability to adapt to changes in food prices over time.
\end{abstract}

Keywords: Canada, consumer vulnerability, food prices, consumer awareness

\section{Introduction}

Retail prices have historically been stable compared to developing economies over the last 30 years (Galloway, 2014). However, food prices in Canada have increased significantly in recent years (Schroeder, Hoffmann and Loy, 2016). Since 2012 the prices of some food products have increased by more than 25\% (Van Der Linde, 2015). In 2016, drastic increases in the prices of some foods, most notably cauliflower, were very much at the forefront of consumer consciousness (McEwan, 2017).

\subsection{Factors Affecting Food Prices}

The reasons for the surge in food prices are not fully established. Some have pointed to an under-performing Canadian Dollar which has affected domestic importers buying power. Historically, such phenomena are not unusual (Tamilia and Charlebois, 2007; Charlebois, Tamilia and Labrecque, 2007; Jessri et al., 2014), but the Canadian currency has experienced unprecedented devaluations from 2014 to 2016 (Powell, 2016; Charlebois and Foti, 2017). Climate change also appears to have played a role. California, a major supplier of produce to Canada, has been affected by a lingering drought for years, predictably impacting agricultural productivity of the region (Charlebois et al., 2016). Consequently, price hikes were sudden and unexpected by many Canadian households. During 2015 and early 2016, food inflation was higher in Canada than in other industrialized countries (Vieira, 2016). Some question why Canada has become a unique case. Due to the discrepancies in food inflation between countries, consumers and researchers alike are growing wary about the rationale used to justify retail price changes (Sagan, 2016).

Much of the extant literature is concerned with identifying the impact of turbulent economic conditions on subdued disposable income (Dimitri and Rogus, 2014; Ferguson, 2014) and the resultant changes in shopping patterns. These conditions influence food choices, food security, and access to and availability of food. Price sensitivity is countercyclical such that it rises as the economy weakens (Gordon et al., 2013). Moreover, after a recession, consumers tend to reduce their spending rather than revert to higher spending, as illustrated by the theory of cyclical asymmetry (Deleersnyder et al., 2004). In addition to reduced income, consumers face further vulnerability by increased food prices over the same period during a recession. Industry players (i.e. suppliers, shippers, retailers) face higher costs due to environmental factors (i.e., rising inflation, and competition), and pass them onto consumers (Ferguson, 2014). 


\subsection{Consumer Behaviour}

Grocery shopping, by virtue of its high flexibility and frequency, is a malleable behaviour. In addition, conventional and non-durable groceries have a relatively high price elasticity (Bunte et al., 2010; Marian et al., 2014). Hence, consumers can easily react to changes in discretionary income and increased prices (Ma et al., 2011; Charlebois, McCormick and Juhasz, 2016). A study by Somervuori \& Ravaja, (2014) was one of the few previous studies that examined how shopping behaviours change in response to fluctuating food prices, as opposed to reduced income. The pertinent findings showed that price-promoted, national brand food products induce higher positive emotions than private label products that are regularly offered at a low price. Positive emotions lead to a greater purchase intent. (Somervuori \& Ravaja, 2014). However, even with greater purchase intent for promoted products, there is less loyalty to individual national grocery brands; these effects last even after the economic turmoil has subsided (Garretson et al., 2002).

Consumers are better informed (Estelami et al., 2001), and exhibit a stronger degree of price consciousness, defined as "the degree to which the consumer focusses exclusively on low prices" (Lichtenstein et al., 1993). Price consciousness is generally associated with a decreased willingness to pay. Price conscious consumers engage in trade-offs among non-price factors that influence grocery shopping behaviour (i.e., convenience and quality).

One of the ways consumers attempt to plan their purchasing is with flyers, a largely pre-shopping behaviour. However, there is a decreasing level of trust consumers have on the reliability of flyers as a source of information. Consumers who are highly prone to consulting flyers will not question the credibility of the promotional offers featured in flyers, showing a significant negative relationship between market scepticism and flyer proneness (Grewal et al., 2012) Generally, deal-seeking consumers who have a low level of pricing tactic persuasion knowledge will consult flyers; often, these consumers are those who are coupon-prone.

Shoppers faced with volatile food prices are often compelled to seek out cheaper alternatives (Gordon et al., 2013). These cheaper alternatives manifest themselves in two main fashions: promoted products and cheap national brands. The preference for promoted products can be seen in how shoppers view national and private brands. An increase in national food brands and a concurrent decrease in income decreases loyalty, and increases the purchase of alternative brands (Nasser et al., 2011; Quelch and Harding; Ma et al., 2011).

Promoted items have a significant impact on consumer behaviour, even during times of undistinguished price volatility. Approximately $30 \%$ to $40 \%$ of purchases made in supermarkets were promoted (Walters and Jamil, 2002). Price conscious consumers are one of the likely many consumer groups to buy promoted items in the pursuit of deals where expected quality exceeds the price paid (Gazquez-Abad et al., 2014).

However, increased knowledge is often an increase in perceived knowledge. Interestingly, society's ability to accurately recall prices is decreasing (Estelami et al., 2001). Hence, 40-50\% of purchases are made by consumers using perceived prices rather than actual prices (Murthi and Rao, 2012; Charlebois, Sterne, Buhr, 2014). An increased reliance on expected prices suggests higher consumer uncertainty and price sensitivity. A potential cause may be the increased financial and normative pressure consumers are under, to change the way they shop (Hampson and McGoldrick, 2013; Charlebois, Creedy and von Massow, 2015). Additionally, under times of financial uncertainty, perceived price awareness increases. Consumers report more negative price effects than positive (Peine, Heitman and Hermann, 2009). Prospect Theory, initially proposed by Kahneman and Tverskey (1979), postulates that consumers react more to losses (price increases) than gains. Thus, consumers can pursue loss aversion by adopting the various shopping behaviours.

While many studies have explored consumer behaviour in a broad range of contexts, little research has been done with respect to consumer behaviours under conditions of fluctuating prices, particularly in developed countries (Charlebois and Camp, 2007). Other studies have also shown that consumers are motivated to reduce their vulnerability caused by an unpredictable market. Vulnerability to food prices is not solely defined by fluctuations in price. Shopping behaviour (e.g. making lists, budgeting, substituting alternate products) and the overall macro-economic environment (such as inflation) that consumers must operate in are determinants. Market demographics (e.g. age, income, gender, region) will also impact how vulnerable a consumer feels. Consumers also have varying degrees of information or understanding regarding market intelligence (e.g. deal-seeking behaviours within or between stores). All four of these broad factors (shopping behaviours, food price fluctuations, demographics, and market intelligence) will determine overall vulnerability to increased food prices (Figure 1). Examining one broad factor and ignoring the rest will not provide a comprehensive picture of consumer vulnerability or adaptability. 


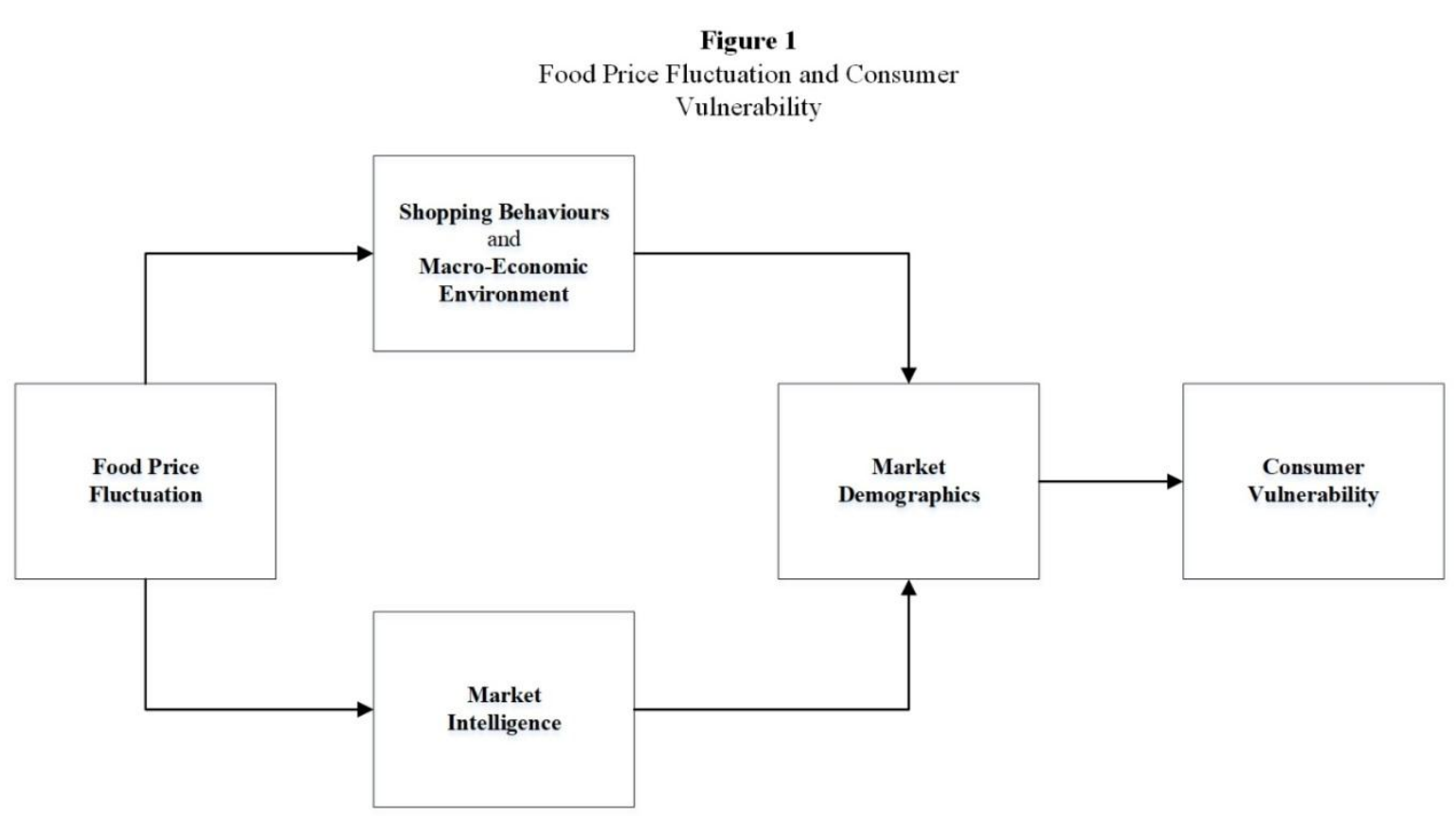

Figure 1. Food price fluctuation, consumers' market intelligence, demographics, and shopping behaviours within the overall macro-economic environment all contribute to consumer vulnerability

This study seeks to examine how Canadian consumers perceived their vulnerability to increases in food prices, which demographic or other characteristics impacted perceived vulnerability, and identified behaviours consumers exhibited to reduce their vulnerability during a food price surge during 2015-2016.

\section{Methods}

This study is based on a quantitative analysis of primary data obtained from a survey on pre-shopping behaviour and retail food prices. The survey was a Cross-Canada study, administered bilingually. Given the exploratory nature of the study, an inductive-driven process utilizing a quantitative analysis of primary data will be used. For convenience and validity, all respondents must have resided in Canada for twelve months and have been at least eighteen years old at the time of the study.

The effect of fluctuating food prices on market intelligence and shopping habits may vary among consumer groups. A demographic component of the study is necessary to identify which consumer groups make major changes from those that maintain similar behaviour to position additional research questions to understand why such changes occur (Hampson and McGoldrick, 2013). The survey tool was organized into four parts. Part 1 ensured that each participant was of 18 or older and was responsible for buying all or most of their own groceries. Part 2 assessed the respondents' change in price consciousness as a reaction to fluctuating food prices, and sought to understand how consumers have mitigated the effects of price volatility through both pre-shopping and in-store behaviours while purchasing food. Part 3 assessed the respondents' perceived vulnerability to and awareness of fluctuating food prices. Finally, Part 4 posed general demographic questions such as gender, age, education, household income, and location.

Recruitment was random. This methodological approach is consistent with similar studies on food consumption in Canada (Charlebois et al., 2016; Iwai, Kagaya and Alford, 2012). The survey was made available online (including posted on social media outlets) and invitations were widely distributed across the country to several regions and socio-economic groups, to ensure various regional and demographic groups were represented in the findings. Geographical locations for the survey were chosen with the aim of achieving the highest possible maximum of geographical and socioeconomic scattering of consumers' characteristics.

The data collection was conducted over a 23-day period in October 2016. To obtain an effective measuring tool, we conducted a pretest before handing out the official questionnaire to make necessary revisions. All questions were translated into French in a way that preserved the intent and tone of the original English text. Since this was an exploratory study, a sample size of 1004 was thought to be representative and adequate. Participants were given the option to be entered in a draw for a small gift certificate to a restaurant of their choosing. Each 
respondent took an average of 2.6 minutes to fill out the survey and there was a 99\% completion rate. Cross-tabs and correlations were conducted and considered demographic data as independent variables. These were done to evaluate which demographic group were more affected by fluctuating food prices.

\section{Results}

Of the 1004 respondents, $91.6 \%$ buy all of their own groceries for themselves or their families. In response to questions about awareness of changes in food prices and concerns about food security, most participants did notice an increase in the 12 months prior to October 2016 (60.3\%). The majority of consumers also became more price-conscious in that time (69.9\%). A small proportion were more concerned about food security than they had been before food prices rose $(24.3 \%)$.

$53.4 \%$ of respondents have changed the way they shop for groceries to reduce the amount of money they spend on food during the 12 month period prior to October 2016 in response to fluctuating food prices. Consumers used a variety of tactics to attempt to reduce the amount of money they spent on food (Table 1).

Table 1. Survey participants were asked to select all the pre-shopping behaviours that they have engaged in to reduce the amount they and their families spend on food in the last 12 months in response to fluctuating food prices. The table describes the percentage of survey respondents who engaged in that behaviour.

\begin{tabular}{ll}
\hline Behaviour & Percent of Consumers \\
\hline Make a shopping list & $95.1 \%$ \\
Look for deals (fliers, coupons) & $59.9 \%$ \\
Stockpiling on-sale items & $56.9 \%$ \\
Plan to shop at stores based on deals/sales & $53.7 \%$ \\
Find alternative foods to buy due to increased prices & $41.3 \%$ \\
Set a budget for shopping trips & $15.9 \%$ \\
\hline
\end{tabular}

\subsection{Factors Affecting Vulnerability or Adaptability}

The gender distribution from our survey was consistent with other surveys of the same type (Charlebois et al., 2016). Of our sample, $54.9 \%$ of the respondents were female. Due to fluctuating food prices, Female (59.1\%) respondents have changed shopping habits more so than Men (34.1\%). Female respondents $(70.1 \%)$ are more price conscious than Male respondents (39.2\%). Male (25.9\%) respondents are slightly more concerned than Female (20.7\%) respondents about food security.

Income also garnered some interesting results. Respondents in households with $\$ 80-100 \mathrm{~K}$ seem to have been more affected by fluctuating food prices than other income groups (above and below). Consumers within this demographic have changed their shopping more than any other income group $(\mathrm{p}<0.05)$, and are more likely to become price conscious this past year, due to fluctuating food prices $(\mathrm{p}<0.05)$. Education levels and their significance were also captured in the survey. Respondents with a high school diploma (59.1\%) have changed shopping habits more so than respondents with university degrees $(49.5 \%)$ or graduate degrees $(46.3 \%)(\mathrm{p}<0.05)$. Respondents with graduate degrees $(46.3 \%)$ or university degrees $(33.3 \%)$ are more likely to look at flyers than respondents with high school diplomas $(27.0 \%)(\mathrm{p}<0.05)$.

Older respondents were more likely to change shopping habits due to fluctuating food prices than younger ones $(\mathrm{p}<0.05)$. Consumers aged 46 and older would use flyers $(60.5 \%$ of these respondents) and change what food they eat $(47.3 \%)$ more often than other age categories $(\mathrm{p}<0.05)$. Consumers under the age of 21 have changed shopping habits due to fluctuating food prices (59.7\%) (Table2).

Table 2. Age-specific findings of consumer adaptability. Consumers were asked how likely they were to engage in a particular behaviour to attempt to reduce their cost of food. Percentages indicate how many of that age group indicated that they would engage in that behaviour. Asterisks indicates the age group that was more likely to engage in a particular behaviour, relative to the other age groups for that behaviour

\begin{tabular}{lllll}
\hline Behaviour & Under 21 & $\mathbf{2 1 - 3 5}$ & $\mathbf{3 6 - 4 5}$ & Over 46 \\
\hline Changed shopping habits (in general) & $\mathbf{5 9 . 7 \%}$ & $47.2 \%$ & $44.4 \%$ & $57.1 \%$ \\
Browse fliers before shopping & $15.7 \%$ & $34.8 \%$ & $44.4 \%$ & $\mathbf{6 0 . 5 \%}$ \\
Change what they eat based on what is on sale & $28.9 \%$ & $37.2 \%$ & $25.9 \%$ & $\mathbf{4 7 . 3 \%}$ \\
\hline
\end{tabular}

\subsection{Region-Specific Findings}

Consumers in all regions of Canada were conscious of increasing prices in 2015-2015, those in Quebec reported 
higher awareness. Consumers in the Canadian provinces of Ontario, Quebec, and British Columbia were more likely to change their shopping habits than those in the Prairies or Atlantic regions. (Table 3). Consumers in Ontario were more likely to engage in such pre-shopping habits as planning shopping trips, stockpiling on-sale items, or to actively seek cheaper alternatives. Those in Quebec were most likely to plan meals before grocery shopping. Consumers in Northern Communities seem to worry more about food prices than consumers in other provinces. Consumers in Quebec were more likely to have noticed food price increases over this past year, more so than consumers in other provinces. Generally, respondents from the Atlantic and the Prairies seem to have been less affected by fluctuating prices.

Consumers in Northern Communities were likely to plan meals, stockpile sale items, and actively seek out cheaper alternatives. No other pre-shopping behaviour was of statistical significance. (Table 3).

Table 3. Region-specific findings of consumer adaptability. Percentages indicate how many participants in each region indicated that they agreed with a statement or would engage in a particular behaviour. Bold text indicates which group was most likely to engage in a particular behaviour; asterisks indicate that a result was not statistically significant

\begin{tabular}{lllllll}
\hline Question & BC & Prairies & Ontario & Quebec & Atlantic & Northern \\
\hline Change shopping habits (in general) & $\mathbf{5 7 . 0 \%}$ & $41.3 \%$ & $52.8 \%$ & $55.2 \%$ & $49.7 \%$ & $*$ \\
Conscious of fluctuating prices & $64.5 \%$ & $63.1 \%$ & $68.6 \%$ & $\mathbf{7 1 . 4 \%}$ & $64.5 \%$ & $*$ \\
Planned Shopping trips (e.g. lists, budgets) & $55.8 \%$ & $50.1 \%$ & $\mathbf{6 2 . 5 \%}$ & $53.3 \%$ & $42.7 \%$ & $*$ \\
Plan meals & $30.1 \%$ & $26.6 \%$ & $41.6 \%$ & $\mathbf{4 7 . 2 \%}$ & $34.0 \%$ & $12.4 \%$ \\
Browse fliers before shopping & $30.0 \%$ & $33.1 \%$ & $\mathbf{6 2 . 6 \%}$ & $58.8 \%$ & $22.1 \%$ & $*$ \\
Actively looking for cheaper alternatives & $23.0 \%$ & $42.4 \%$ & $\mathbf{5 5 . 5 \%}$ & $41.1 \%$ & $41.5 \%$ & $31.7 \%$ \\
Stockpiling on-sale items & $61.5 \%$ & $42.4 \%$ & $\mathbf{6 5 . 9 \%}$ & $60.2 \%$ & $51.9 \%$ & $39.2 \%$ \\
\hline
\end{tabular}

\subsection{Increased Vulnerability}

In addition to the demographic and regionally specific findings, the following factors or combined factors contributed to increased vulnerability. Less educated, lower-earning women feel more vulnerable than any other demographic groups $(\mathrm{p}<0.05)$. Households with dependents were more likely to feel less food secure than a year ago $(\mathrm{p}<0.05)$. More educated and higher income earning respondents were more likely to become more price conscious this past year due to fluctuating prices $(\mathrm{p}<0.05)$.

\section{Discussion}

These results help us better understand how consumers acquire knowledge about food and how they could be influenced by the food store environment. As an exploratory study, the purpose is intended to gain preliminary insights, rather than draw firm conclusions. Sample was limited by the online distribution of the survey tool. This study did not identify specific food items that consumers were most concerned about or affected by. Food insecurity may affect some food categories differently. Thus, it is suggested that in future research, a range of food products for measurement be explored so that the construct validity can be less ambiguous.

This exploratory research has added to our understanding of dimensions of consumer behaviour pertaining to what influences shopping behaviours and vulnerabilities regarding fluctuating food prices in Canada. Even though these results may be considered intuitive, it is our belief that there is a connection between - and willingness for consumers to self-protect has never been made conceptually until now. Pre-shopping behaviours demonstrated by respondents are indicative of the willingness to self-protect. Shopping lists and meal planning were the most common pre-shopping behaviours, but few Canadians were planning a shopping trip based on a budget.

Fluctuating food prices clearly have affected Canadians this past year. With cross-tabulations, our findings suggest that there are significant socio-demographic trends related to consumer vulnerability and fluctuating food prices with respect to gender, income, age, education, and region. all seem to be key determinants in how Canadians respond to fluctuating food prices.

\subsection{Gender}

The role of gender in consumer behaviour and market intelligence is somewhat contentious. Historically, men did not play an active role in buying groceries. Studies have shown that men are not as concerned with food 
prices, and are less price conscious; they do not compare prices, stick to a defined budget, buy promoted items nor are price sensitive (Mortimer and Weeks, 2011). As such, several studies have shown that women are more likely to change shopping behaviours than men (Rosa-Diaz, 2004; Hillier et al., 2015, Mortimer and Weeks, 2011), while men are more likely to spend more money on groceries than women. However, other studies have found gender to play an insignificant role in price consciousness (Ailawadi et al., 2001; Gazquez-Abad et al., 2014; Peric, 2015). Less defined gender roles in households may explain the inconsistent findings in previous studies. This study found that female respondents were more likely to change shopping habits and be more price conscious, but that male respondents were slightly more concerned about food security.

\subsection{Income}

Literature that has predominantly investigated market intelligence and behaviours of lower income consumer groups is decontextualized and therefore limited in its application to this study. Low- and middle-income groups, with or without dependents, have consistently demonstrated deal-seeking grocery shopping behaviours (Ma et al., 2011; Hillier et al., 2015; Peric, 2015; Powell et al., 2016). This includes travelling further and more frequently to buy from cheaper discount stores, consulting flyers, and finding alternatives (Hillier et al., 2015).

Interestingly, Ma et al., (2011) found that, under periods of macroeconomic turbulence, high-income consumer groups also change shopping behaviours. These results may point to that middle- and high-income households with dependents are likely to increase market intelligence, price consciousness, and deal-seeking behaviours to reduce their family's consumer vulnerability (Rosa-Diaz, 2004).

\subsection{Education}

Education is also a determinant for premium food choices (Erdem et al., 2010; Levy et al. 1998). Highly educated customers are more likely to consider alternatives when market conditions rapidly fluctuate, or perceived risks are altered. However, our study suggests that less-educated respondents (having completed high school but no post-secondary education) were more likely to change shopping habits, possibly due to lower earing potential and thus lower disposable income than higher-educated Canadians.

\subsection{Age}

Numerous studies (i.e., Ailawadi et al., 2001; Gazquez-Abad et al., 2014; Peric, 2015) show that age is one of the most significant demographic factors to influence consumer behaviour. Interestingly, these studies unanimously agree that increases in age are directly related to deal-seeking behaviours, particularly consulting flyers and finding alternatives. Middle-aged consumer groups are also shown to have a relatively high degree of market intelligence, which, as previous literature suggests, may result in an increase of buying promoted goods and finding alternatives (Rosa-Diaz, 2004). Our findings were consistent with previous studies.

\subsection{Region}

While sample sizes of participants in Northern Communities were not large enough to warrant statistical significance in all cases, this study does provide some insight into food security and vulnerability issues in Northern Canada. Consumers in Northern Communities felt more vulnerable than food prices than consumers in other regions. Given that food in the North is more expensive, on average, than the rest of Canada (Galloway, 2014), we would suggest that Northern communities would be further impacted by increasing food prices due to a higher proportion of their income already going towards food. Any increase would likely see a further increase in perceived vulnerability, price consciousness, and behaviours geared towards balancing the amount spent on food and nutrition for individuals and families.

Regions such as Ontario, Quebec, and British Columbia were generally more price conscious and actively sought out cheaper alternatives or engaged in other pre-shopping behaviours than the Prairies or Atlantic Canada. This is perhaps explained by the excessive cost of living in all three of those provinces. Major cities in these regions are among the top 5 most expensive to live in Canada (Canadian Real Estate Association, 2017). In these regions, even if a family has a higher income relative to their counterparts in the Prairies or Atlantic provinces, such a large portion of monthly income is directed to housing that there may be less income available to provide other necessities such as food. Therefore, vulnerability to increasing food prices and the behaviours associated with attempts to decrease vulnerability may be more prevalent in these regions. However, it was surprising that consumers in Atlantic provinces did not report higher perceived vulnerability during the 2015-2016 period.

\section{Conclusion}

Canadian consumers felt more vulnerable due to fluctuating food prices but demonstrated adaptability. This study further emphasized that shoppers are now more knowledgeable, purposeful and price conscious than 
before. (Hampson and McGoldrick 2013). Technology and recent turbulent macroeconomic developments play significant roles in driving this awareness (Grewal et al., 2012). Technology has empowered shoppers to be more in tune with price fluctuations and determine price fairness. While traditional store flyers might provide a faster response than other forms of advertising, new technology and media are creating instant access opportunities for flyers (Ziliani et al., 2014). Digital flyers (i.e., the online version of the print flyer) are available on websites, apps (e.g., flyer aggregators) and social networks, which allow for instant dissemination of grocery market prices. Social networks have also allowed for a proliferation of crowd-sourced reviews, which provide consumers a perceived validity to product quality. Beyond influencing individual purchasing decisions, social networks have also simplified group buying opportunities. These enhance consumer value perceptions as consumers collectively become more aware of promotions and their ability to capitalize on such promotions (Grewal et al., 2012).

Due to the positive relationship of impulse buying and disposable income, identified by Beatty and Ferrell (1998), consumers should plan their grocery trips, such as making lists, to lessen their vulnerability. However, while the literature shows that planning is a theoretically useful tool, it is not often pursued as a habit to reduce consumer vulnerability. Some habits are difficult to curtail. After all, being frugal does require more effort.

\section{References}

Ailawadi, K. L., Neslin, S. A., \& Gedenk, K. (2001). Pursuing the value-conscious consumer: store brands versus national brand promotions. Journal of marketing, 65(1), 71-89. https://doi.org/10.1509/jmkg.65.1.71.18132

Beatty, S. E., \& Ferrell, M. E. (1998). Impulse buying: Modeling its precursors. Journal of retailing, 74(2), 169-191. https://doi.org/10.1016/S0022-4359(99)80092-X

Bunte, F. H., J., van Galen, M. A., Kuiper, W. E., \& Tacken, G. (2010). Limits to growth in organic sales. De Economist, 158(4), 387-410. http://dx.doi.org/10.1007/s10645-010-9152-3

Canadian Real Estate Association, RBC Economics Research (March 2017). Housing Trends and Affordability. Retrieved from http://www.rbc.com/economics/economic-reports/pdf/canadian-housing/house-mar2017.pdf.

Charlebois, Sylvain, and Ronald D. Camp (2007). Environmental uncertainty and vertical integration in a small business network: The case of Natural Valley Farms Inc. Journal of Enterprising Communities: People and Places in the Global Economy, 1(3), 252-267. https://doi.org/10.1108/17506200710779558

Charlebois, S., Tamilia, R. D., \& Labrecque, J. (2007). Food marketing and obesity: a public policy and channels perspective. Innovative Marketing, 3(1), 83-100.

Charlebois, S., Sterne, R. H., \& Buhr, M. (2014). Sharing and preparing: cross-institutional, food security-based knowledge in Canada. International Journal of Sustainable Development \& World Ecology, 21(6), 532-539. https://doi.org/10.1080/13504509.2014.971905

Charlebois, S., Creedy, A., \& von Massow, M. (2015). "Back of house"-focused study on food waste in fine dining: the case of Delish restaurants. International Journal of Culture, Tourism and Hospitality Research, 9(3), 278-291. https://doi.org/10.1108/IJCTHR-12-2014-0100

Charlebois, S., McCormick, M., \& Juhasz, M. (2016). Meat consumption and higher prices: Discrete determinants affecting meat reduction or avoidance amidst retail price volatility. British Food Journal, 118(9), 2251-2270. https://doi.org/10.1108/BFJ-03-2016-0121

Charlebois, S., Juhasz, M., Foti, L., \& Chamberlain, S. (2017). Food Fraud and Risk Perception: Awareness in Canada and Projected Trust on Risk-Mitigating Agents. Journal of International Food \& Agribusiness Marketing, 1-18. https://doi.org/10.1080/08974438.2017.1331149

Charlebois, S., Tyedmers, P., Bailey, M., \& Harris, J. (2016). Canada's food price report 2017. Halifax, Canada: Dalhousie University. 20 p. Retrieved from https://www.dal.ca/content/dam/dalhousie/pdf/management/News/News\%20\&\%20Events/21135-Food-Pric e-Report-Eng-2017-Final.pdf.

Charlebois, S., \& Foti, L. (2017). Using a Live Case Study and Co-opetition to Explore Sustainability and Ethics in a Classroom: Exporting Fresh Water to China. Global Business Review, 18(6), 1400-1411. https://doi.org/10.1177/0972150917713086

Deleersnyder, B., Dekimpe, M. G., Sarvary, M., \& Parker, P. M. (2004). Weathering tight economic times: The 
sales evolution of consumer durables over the business cycle. Quantitative Marketing and Economics, 2(4), 347-383. https://doi.org/10.1007/s11129-004-0137-x

Dimitri, C., \& Rogus, S. (2014). Food choices, food security, and food policy. Journal of International Affairs, 67(2), 19.

Erdem, T., Katz, M. L., \& Sun, B. (2010). A simple test for distinguishing between internal reference price theories. Quantitative Marketing and Economics, 8(3), 303-332. https://doi.org/10.1007/s11129-010-9087-7

Estelami, H., Lehmann, D. R., \& Holden, A. C. (2001). Macro-economic determinants of consumer price knowledge: A meta-analysis of four decades of research. International Journal of Research in Marketing, 18(4), 341-355. https://doi.org/10.1016/S0167-8116(01)00044-1

Ferguson, J. L. (2014). Implementing price increases in turbulent economies: Pricing approaches for reducing perceptions of price unfairness. Journal of Business Research, 67(1), 2732-2737. https://doi.org/10.1016/j.jbusres.2013.03.023

Garretson, J. A., Fisher, D., \& Burton, S. (2002). Antecedents of private label attitude and national brand promotion attitude: similarities and differences. Journal of Retailing, 78(2), 91-99. https://doi.org/10.1016/S0022-4359(02)00071-4

Gázquez-Abad, J. C., Martínez-López, F. J., \& Barrales-Molina, V. (2014). Profiling the flyer-prone consumer. Journal of Retailing and Consumer Services, 21(6), 966-975. https://doi.org/10.1016/j.jretconser.2014.08.019

Gordon, B. R., Goldfarb, A., \& Li, Y. (2013). Does Price Elasticity Vary with Economic Growth? A Cross-Category Analysis. Journal of Marketing Research, 50(1), 4-23. https://doi.org/10.1509/jmr.11.0162

Grewal, D., Roggeveen, A. L., Compeau, L. D., \& Levy, M. (2012). Retail value-based pricing strategies: New times, new technologies, new consumers. Journal of Retailing, 88(1), 1-6. https://doi.org/10.1016/j.jretai.2011.12.001

Hampson, D. P., \& McGoldrick, P. J. (2013). A typology of adaptive shopping patterns in recession. Journal of Business Research, 66(7), 831-838. https://doi.org/10.1016/j.jbusres.2011.06.008

Hillier, A., Smith, T., Cannuscio, C. C., Karpyn, A., \& Glanz, K. (2015). A discrete choice approach to modeling food store access. Environment and Planning B: Planning and Design, 42(2), 263-278. https://doi.org/10.1068/b39136

Iwai, N., Kagaya, T., \& Alford, R. A. (2012). Feeding by omnivores increases food available to consumers. Oikos, 121(2), 313-320. https://doi.org/10.1111/j.1600-0706.2011.20128.x

Jessri, M., Abedi, A., Wong, A., \& Eslamian, G. (2014). Nutritional quality and price of food hampers distributed by a campus food bank: A Canadian experience. Journal of health, population, and nutrition, 32(2), 287.

Kahneman, D., \& Tversky, A. (1979). Prospect theory: An analysis of decision under risk. Econometrica, 47(2), 263-291. https://doi.org/10.2307/1914185

Levy, A. S., \& Fein, S. B. (1998). Consumers' ability to perform tasks using nutrition labels. Journal of Nutrition Education, 30(4), 210-217. https://doi.org/10.1016/S0022-3182(98)70321-8

Lichtenstein, D. R., Ridgway, N. M., \& Netemeyer, R. G. (1993). Price perceptions and consumer shopping behavior: a field study. Journal of marketing research, 234-245. https://doi.org/10.2307/3172830

Ma, Y., Ailawadi, K. L., Gauri, D. K., \& Grewal, D. (2011). An empirical investigation of the impact of gasoline prices on grocery shopping behavior. Journal of Marketing, 75(2), 18-35. https://doi.org/10.1509/jmkg.75.2.18

Marian, L., Chrysochou, P., Krystallis, A., \& Thøgersen, J. (2014). The role of price as a product attribute in the organic food context: An exploration based on actual purchase data. Food Quality and Preference, 37, 52-60. https://doi.org/10.1016/j.foodqual.2014.05.001

McEwan, G. (2017). Fresh-produce growers left behind by trends? Horticulture Week, 18.

Mortimer, G. S., \& Weeks, C. S. (2011). Grocery product pricing and Australian supermarket consumers: Gender differences in perceived importance levels. The International Review of Retail, Distribution and Consumer Research, 21(4), 361-373. https://doi.org/10.1080/09593969.2011.596553

Murthi, B., \& Rao, R. C. (2012). Price awareness and consumers' use of deals in brand choice. Journal of Retailing, 88(1), 34-46. https://doi.org/10.1016/j.jretai.2011.07.001 
Nasser, R., Cook, S., Bashutski, M., Hill, K., Norton, D., Coleman, J., ... \& Charlebois, S. (2011). Consumer perceptions of trans fats in 2009 show awareness of negative effects but limited concern regarding use in snack foods. Applied Physiology, Nutrition, and Metabolism, 36(4), 526-532. https://doi.org/10.1139/h11-045

Paswan, A. K, Crawford, J.C, Ngamsiriudom, W., \& Nguyen, T. (2014). Consumer reaction to price increase: an investigation in gasoline industry. Journal of Product \& Brand Management, 23(3), 220-229. https://doi.org/10.1108/JPBM-09-2013-0377

Peine, K., Heitmann, M., \& Herrmann, A. (2009). Getting a feel for price affect: A conceptual framework and empirical investigation of consumers' emotional responses to price information. Psychology and Marketing, 26(1), 39-66. https://doi.org/10.1002/mar.20261

Peris, T. (2015). The impact of price reduction on behavioral responses of consumers. Economic and Social Development (Book of Proceedings), 5th Eastern European Economic and Social Development. 2012.

Powell, J. (Jan 16, 2016. Boom, bust, peg, parity-the Canadian Dollar has seen it all before. The Globe and Mail. Retrieved from

https://www.theglobeandmail.com/report-on-business/rob-commentary/boom-bust-peg-parity-the-canadiandollar-has-seen-it-all-before/article28227022/.

Powell, L. M., Kumanyika, S. K., Isgor, Z., Rimkus, L., Zenk, S. N., \& Chaloupka, F. J. (2016). Price promotions for food and beverage products in a nationwide sample of food stores. Preventive Medicine, 86(great read look at references for similar work), 106-113. https://doi.org/10.1016/j.ypmed.2016.01.011

Quelch, J. A., \& Harding, D. (1996). Brands versus private labels: fighting to win. Harvard Business Review, 37(1), 99-109.

Rosa-Díaz, I. M. (2004). Price knowledge: Effects of consumers' attitudes towards prices, demographics, and socio-cultural characteristics. Journal of Product \& Brand Management, 13(6), 406-428. https://doi.org/10.1108/10610420410560307

Sagan, A. (2016, January 13). As loonie slides, prices of fruits and vegetables rise. The Globe and Mail), B7.

Schroeder, K. J., Hoffmann, A., \& Loy, J. P. (2016). The distribution of food retail prices and the euro changeover: signpost items versus occasional goods. Agribusiness, 32(1), 93-112. https://doi.org/10.1002/agr.21431

Somervuori, O., \& Ravaja, N. (2013). Purchase behavior and psychophysiological responses to different price levels. Psychology \& Marketing, 30(6), 479-489. https://doi.org/10.1002/mar.20621

Tamilia, R. D., \& Charlebois, S. (2007). The importance of marketing boards in Canada: a twenty-first century perspective. British Food Journal, 109(2), 119-144. https://doi.org/10.1108/00070700710725491

Van Der Linde, D. (2015, September 01). Grocery chains tap new market; Odd-looking fruits and vegetables now being sold at discount prices. National Post.

Vieira, P. (2016, January 22). Canada inflation climbs on higher food prices; The all-items consumer-price index advanced $1.6 \%$ in December. Wall Street Journal.

Walters, R., \& Jamil, M. (2002). Measuring cross-category specials purchasing: theory, empirical results, and implications. Journal of Market-Focused Management, 5(1), 25-42. https://doi.org/10.1023/A:1012523427988

Ziliani, Cristina, and Marco Ieva. (2015). Retail shopper marketing: the future of promotional flyers. International Journal of Retail \& Distribution Management, 43(6), 488-502. https://doi.org/10.1108/IJRDM-02-2014-0022

\section{Questionnaire: Shopping Habits in Food Survey}

\section{Welcome!}

You are invited to take part in an anonymous survey study on pre-shopping behaviors in food. The main objective of this research project is to uncover interesting consumer behaviour when food prices change in food retailing. This survey is conducted by the Institute for Strategic Foresight at Dalhousie University. The lead researcher for this project is Dr. Sylvain Charlebois (Sylvain.charlebois@dal.ca, (902) 494-2582. He can be 
contacted should you have any questions/comments.

By filling out the survey you are consenting to participate. The survey should take no more than 2 to 3 minutes of your time. The survey will end on October 31, 2016. Your participation to this survey is voluntary but very important because it will help us better understand how consumers prepare for food purchases and they are influenced by their store experience. Survey results will be shared broadly on our website and may be published in a peer-reviewed academic journal.

Respondents need to be 18 years old to participate. If for any reason you do not want to complete the survey, you can exit at any time. You are free to skip any questions as well. You need to have been living in Canada for at least the last 12 months in order to qualify for this survey. Please note that because data collection occurs via the internet, complete confidentiality of the data cannot be guaranteed. There are no risk to participate and no direct benefits for your participation. You cannot withdraw data once the survey is completed given the anonymity of the survey.

As an expression of our gratitude, we would like to offer you the opportunity to enter a draw to win one of four $\$ 50$ gift certificates to a local restaurant near where you live. At the end of the questionnaire you will find instructions on how to enter. The draw is optional and personal information will be kept in confidence and will only used for the draw. You can print this consent form for your records by clicking here.

This project has been reviewed by the Research Ethics Board for compliance with federal guidelines for research involving human participants. If you have any questions regarding your rights and welfare as a research participant in this study (REB\#XXXXXX), please contact: Research Ethics; Dalhousie University; ethics@ dal.ca; 902-494-3423. You do not waive any legal rights by agreeing to take part in this study.

I am at least 18 years old and consent to participate (1)

I am not 18 years old and DO NOT consent to participate (2)

If I am not 18 years old and D... Is Selected, Then Skip To End of Survey

What is your gender?

- Male (1)

- Female (2)

- $\quad$ Other (3)

What is your age?

- Under 21 (1)

- $\quad$ Between 21-35 (2)

- $\quad$ Between 36-45 (3)

- 46 or older (4)

What is your education level?

- High School Diploma (1)

- University Degree (2)

- Graduate Degree or Diploma (3)

- $\quad$ Other (4)

How many people live in your household?

- I live alone (1)

- One person with dependents (2)

- $\quad$ Two people (3)

- $\quad$ Two people with dependents (4)

- Three adults or more (5)

Which province or region are you from?

- $\quad$ Ontario (1)

- Quebec (2) 
- $\quad$ Maritimes (3)

- $\quad$ Prairies (4)

- $\quad$ British Columbia (5)

- Northern Communities (6)

What was your household income over the last 12 months?

- Less than $\$ 40,000$ (1)

- $\quad$ Between $\$ 40,001$ and $\$ 80,000$ (2)

- $\quad$ Between \$80,001 and \$100,000 (3)

- $\quad$ More than $\$ 100,001$ (4)

Does someone else buy ALL of your groceries?

- Yes (1)

- No (2)

If the answer is yes, Then Skip To End of Survey

Please indicate your level of agreement with the below statement: In the last 12 months, fluctuating food prices (increasing and decreasing) changed the way I shop for groceries.

- Strongly Disagree (1)

- Disagree (2)

- Neither Agree nor Disagree (3)

- Agree (4)

- Strongly Agree (5)

In the last 12 months, fluctuating food prices (increasing and decreasing) have made me more price conscious when it comes to groceries

- $\quad$ Strongly Disagree (1)

- Disagree (2)

- $\quad$ Neither Agree nor Disagree (3)

- Agree (4)

- $\quad$ Strongly Agree (5)

As a result increasing food prices I have find myself more often: (you can select more than one)

- Looking for deals on groceries

- Finding alternatives to foods I would typically buy due to the increased price of the item

- Planning what I am going to buy before I go to the store

- $\quad$ Stocking up on sale items

If answer is not "Planning what...", Then Skip To "Fluctuating food prices cause me to worry..."

How do you plan your shopping trip? (you can select more than one)

- Make a shopping list

- Browse flyers for deals

- Plan my meals based on what's on-sale

- Set a budget for my shopping trip

- Plan to shop at a store based on deals

Fluctuating food prices cause me to worry about my ability to feed my family while staying on budget.

- Strongly Disagree (1)

- Disagree (2)

- Neither Agree nor Disagree (3) 
- Agree (4)

- $\quad$ Strongly Agree (5)

Over the past 12 months I have noticed an increase on my weekly grocery expenses

- Strongly Disagree (1)

- Disagree (2)

- Neither Agree nor Disagree (3)

- Agree (4)

- $\quad$ Strongly Agree (5)

\section{Copyrights}

Copyright for this article is retained by the author(s), with first publication rights granted to the journal.

This is an open-access article distributed under the terms and conditions of the Creative Commons Attribution license (http://creativecommons.org/licenses/by/4.0/). 